Diet Explains Interpopulation Variation of Plasma Carotenoids and Skin Pigmentation in Nestling White Storks

Author(s): Juan J. Negro, José L. Tella, Guillermo Blanco, Manuela G. Forero, and Juan

Garrido-Fernández

Reviewed work(s):

Source: Physiological and Biochemical Zoology, Vol. 73, No. 1 (January/February 2000), pp. 97101

Published by: The University of Chicago Press

Stable URL: http://www.jstor.org/stable/10.1086/316724

Accessed: 10/10/2012 05:28

Your use of the JSTOR archive indicates your acceptance of the Terms \& Conditions of Use, available at http://www.jstor.org/page/info/about/policies/terms.jsp

JSTOR is a not-for-profit service that helps scholars, researchers, and students discover, use, and build upon a wide range of content in a trusted digital archive. We use information technology and tools to increase productivity and facilitate new forms of scholarship. For more information about JSTOR, please contact support@ jstor.org. 


\section{Diet Explains Interpopulation Variation of Plasma Carotenoids and Skin Pigmentation in Nestling White Storks}

\author{
Juan J. Negro ${ }^{1, *}$ \\ José L. Tella ${ }^{2}$ \\ Guillermo Blanco ${ }^{2}$ \\ Manuela G. Forero \\ Juan Garrido-Fernández ${ }^{3}$ \\ ${ }^{1}$ Department of Applied Biology, Estación Biológica de \\ Doñana Consejo Superior de Investigaciones Cientifícas, \\ Apartado 1056, 41080 Sevilla, Spain; ${ }^{2}$ Department of Biology, \\ University of Saskatchewan, 112 Science Place, Saskatoon, \\ Saskatchewan S7N 5E2, Canada; ${ }^{3}$ Food Biotechnology \\ Department, Instituto de la Grasa, Avenida Padre García \\ Tejero 4, 41012 Sevilla, Spain
}

Accepted 11/11/99

\begin{abstract}
Carotenoids have a dietary origin in birds, but mechanisms by which they are absorbed in the gut, transported in the blood, metabolized at various sites, and deposited in the integument remain poorly understood. Variation in both plasma carotenoid levels and external color may reflect different access to dietary carotenoids or individual physiological differences in the uptake and deposition of carotenoids. We compared total plasma carotenoid concentration in nestling white storks (Ciconia ciconia) from 11 Spanish colonies in two consecutive years. The main food item in one of the colonies was the red swamp crayfish (Procambarus clarkii), a recently introduced species. Storks in the remaining colonies ate a variety of foods but no crayfish. Total plasma carotenoid levels in the colony where crayfish were consumed were about five times higher than in any other colony. These differences were maintained after controlling for the significant interyear variability, as well as for sex, age, and body mass of birds. Skin pigmentation also differed, being intensely orange in storks that consumed crayfish but white (unpigmented) in the remaining individuals. With thin-layer chromatography (TLC) and electronic absorption spectroscopy, astaxanthin was confirmed as the major carotenoid in crayfish as well as in the plasma, skin, and body fat of crayfish-eating storks, whereas lutein was the main carotenoid
\end{abstract}

\footnotetext{
*To whom correspondence should be addressed; e-mail: negro@ebd.csic.es.
}

Physiological and Biochemical Zoology 73(1):97-101. 2000. (C) 2000 by The University of Chicago. All rights reserved. 1522-2152/2000/7301-9923\$03.00 in plasma samples from the other colonies. These results indicate that a newly available carotenoid in the environment, astaxanthin, can be absorbed in large quantities from the gut and be transported in the blood before deposition in different tissues.

\section{Introduction}

Carotenoids have become the focus of investigations into the signaling functions of animal colors (Olson and Owens 1998), particularly in birds (Hill 1991; Gray 1996; Negro et al. 1998). All animals obtain these pigments from their diet (Brush 1990a), and carotenoids can only be deposited in the integument or any other body tissue after being transported in the bloodstream (Fox 1953). However, mechanisms of absorption in the gut, blood transportation, metabolism, and deposition in body tissues are still poorly understood (Hill et al. 1994). Plasma carotenoid levels have been quantified in relatively few wild bird populations, perhaps because no simple and standardized procedure was available to field biologists (but see Tella et al. 1998). The sparse information that is available indicates that species with carotenoid-dependent coloration show higher concentration of plasma carotenoids than do species with no external display of carotenoids (Trams 1969; Hill 1995a). This may seem a trivial observation, but it could be explained by at least two competing hypotheses (Hill 1995a). One hypothesis states that carotenoids are widely available in the environment, but only species displaying integumentary carotenoids have special systems to incorporate them. Alternatively, all species may have similar capacities to incorporate carotenoids, but interspecific differences result from variation in the carotenoid content of their diets.

Studies based on feeding experiments in captivity have demonstrated the strong effect of carotenoid content in the diet to explain intraspecific variation in plumage coloration (Hill 1993). However, age, sex, and seasonal effects have been reported for both plasma carotenoid levels and integumentary colors of captive birds that are fed a uniform diet (Bortolotti et al. 1996; Negro et al. 1998), indicating that other physiological factors are also involved. In field conditions, seasonal variation in blood carotenoid levels have been reported for house finches (Carpodacus mexicanus; Hill 1995b), and sexual differences were observed in the cirl bunting (Emberiza cirlus; Figuerola and Gutiérrez 1998). Diet was unaccounted for in 
both studies, and the authors admitted that they were unable to determine whether variation in circulating levels of carotenoids was due to dietary differences or to individual physiological differences in the uptake of carotenoids. As with interspecific studies, a debate persists (Hudon 1994; Linville and Breitwisch 1997; Olson and Owens 1998) on whether carotenoids are limiting in the environment.

In this study, we compared carotenoid composition and concentration in the plasma of nestling white storks (Ciconia ciconia) that eat mainly the recently introduced red swamp crayfish (Procambarus clarkii), a rich source of crustacean astaxanthin, with those in nestlings that eat the usual diets of fish, arthropods, meat scraps from refuse dumps, and earthworms, all of which contain much lower levels of carotenoids. Our aim was to determine whether the blood system in a given bird species (in this case the white stork) is very specific in the amount and type of carotenoids that it can transport or whether it reflects the amount of carotenoids in the diet. In addition, we investigated other possible sources of individual variation, such as sex, body mass, nestling age, and year effects.

\section{Material and Methods}

Fieldwork was conducted in May-June of 1998 and 1999 in 11 white stork colonies in southern (the provinces of Sevilla, Huelva, and Cádiz) and central Spain (province of Madrid; Fig. 1). The colonies at Jerez, Arahal, and Dehesa de Abajo were sampled during both years of the study, and the remaining colonies were sampled either in 1998 or in 1999. Crayfish were only consumed in the Dehesa de Abajo colony, located in the northern boundary of Doñana National Park. The red swamp crayfish is a nonnative species introduced in southern Spain from the United States in 1973 (Senra and Alés 1992). It has expanded rapidly throughout the Guadalquivir marshes and Doñana National Park, affecting the whole ecosystem (Delibes and Adrián 1987). White storks in the Dehesa de Abajo colony incorporated crayfish in their diet soon after its introduction in the marshes. Most pellets and remains in the nests consisted mainly of crayfish in the early 1980s (Rubio et al. 1983). During the sampling period, crayfish remains were observed in 62 $(82.7 \%)$ of 75 nests with chicks, and they were the only remains in $41(54.7 \%)$ nests with chicks. No crayfish were seen among the nest remains in the other colonies. Instead, we recorded a variety of natural prey (fish, arthropods, earthworms), as well as meat scraps brought by the adult storks from nearby refuse dumps. Individually banded breeding adults $(N=57)$ from these colonies were not observed preying on crayfish during foraging activities (Blanco 1996; J. Marchamalo and G. Blanco, unpublished data).

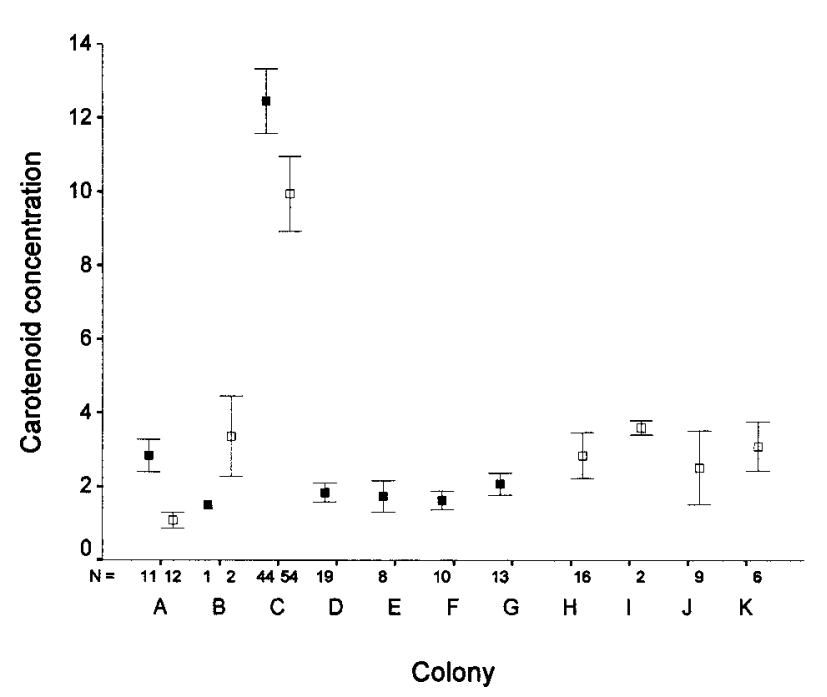

Figure 1. Plasma carotenoid concentration $(\mu \mathrm{g} / \mathrm{mL})$ in nestlings from 11 white stork colonies in Spain. Red swamp crayfish was consumed exclusively in colony C. Codes for colonies: $A$, Jeréz Zoo (Cádiz); $B$, Arahal (Sevilla); $C$, Dehesa de Abajo (Sevilla); $D$, Soto del Real (Madrid); E, Rivas-Vaciamadrid (Madrid); F, Lozoya (Madrid); G, Guadalix (Madrid); H, Marchena (Sevilla); I, Dos Hermanas (Sevilla); J, Aznalcázar (Sevilla); $K$, Villanueva (Huelva). Black dots correspond to 1998 and open dots to 1999; sample sizes are above the codes for colonies.

\section{Biological Materials}

We collected about $0.5 \mathrm{~mL}$ of blood from the brachial veins of 98 nestlings in Dehesa de Abajo and 109 nestlings from the remaining colonies. Blood was transported in coolers to the laboratory on the day of collection and centrifuged to separate blood cells from plasma. Both fractions were frozen for subsequent analyses.

From a freshly dead adult found in April 1999 near the Dehesa de Abajo colony, we collected skin samples (wing and neck) that were bright orange like those of the nestlings, as well as a portion of the red-colored fat. Five live crayfish were also collected for analysis.

\section{Extraction Procedure}

Three volumes of acetone were added to the plasma samples, and then the mixture was centrifuged at 13,000 $g$ for $10 \mathrm{~min}$. The supernatant was analyzed. Skin and fat samples were weighed and then placed in ethyl ether for $2 \mathrm{~h}$. The filtrate containing the carotenoids was evaporated, and the residue was redissolved in acetone before analysis. The crayfish were first ground in a blender and then extracted as described above for skin and fat samples. 
Quantitative Determination of Carotenoids

Total plasma carotenoid content was measured spectrophotometrically (Pharmacia Biotech, Ultrospec 2000 UV/Vis) by using acetone as a solvent and recording absorbance at $476 \mathrm{~nm}$ (Tella et al. 1998). Plasma carotenoid concentration was estimated as micrograms per milliliter of plasma by using a standard curve of lutein. Concentration values are given as mean $\pm \mathrm{SD}$. The absorption maxima for astaxanthin in acetone is $480 \mathrm{~nm}$ (Britton 1995); thus, the actual plasma carotenoid concentration for birds that ingested astaxanthin may be slightly underestimated.

\section{Carotenoid Identification}

For carotenoid separation and comparison with reference astaxanthin, we used thin-layer chromatography (TLC), following the methods of Mínguez-Mosquera and Garrido-Fernández (1989) and Muriana et al. (1993). In addition, electronic absorption spectra were carried out for the different tissues by using a diode-array spectrophotometer (Hewlett-Packard UVVis spectrophotometer $8452 \mathrm{~A}$, controlled by the HP Chem Station V.A. 02.05). As references, we used astaxanthin that was kindly supplied by Hoffman-La Roche (Roche, Madrid), as well as lutein from spinach extracted in our laboratory.

\section{Sex and Age Determination}

Sex and age may affect carotenoid content in bird plasma (Hill et al. 1994; Bortolotti et al. 1996). In the white stork, both sexes look alike, and we resorted to molecular sexing of the birds by using the cellular fraction of the blood as a source of DNA. For this analysis, primers 2945F, cfR, and 3224R were used, following the method of Ellegren (1996). At the time of blood sampling, we recorded body mass and wingchord length from each nestling. Nestling age was estimated according to a regression equation of age on wingchord (age $=5.068+$ $0.117 \times$ wingchord length, $r=0.99, N=12, P<0.01$ ), calculated with data from nestlings whose hatch date was known (Chozas 1983).

\section{Results}

\section{Quantification of Plasma Carotenoids}

Mean plasma carotenoid concentrations were higher in nestlings in the Dehesa de Abajo colony $(11.1 \pm 3.6 \mu \mathrm{g} / \mathrm{mL}, N=$ 98) than in other colonies as a whole $(2.2 \pm 1.0 \mu \mathrm{g} / \mathrm{mL}, N=$ 109; Fig. 1). These differences were significant when colony was used as a grouping factor in one-way ANOVA $\left(F_{10,196}=121.7\right.$, $P<0.001)$. Tukey's HSD tests indicated no significant differences in pairwise comparisons of any of the noncrayfish colonies $(P>0.98)$, whereas differences were all significant $(P<$
0.03 ) between each of those colonies and the Dehesa de Abajo colony.

To examine potential confounding effects on differences in plasma carotenoids related to diet, an ANCOVA was performed with diet (crayfish vs. no crayfish), year, and sex as factors and body mass and age as covariates. There were no significant effects of sex $\left(F_{1,157}=0.4, P=0.53\right)$, age $\left(F_{1,157}=\right.$ $2.9, P=0.09)$, or body mass $\left(F_{1,157}=2.4, P=0.12\right)$ on carotenoid concentration. However, there was a significant year effect $\left(F_{1,157}=5.6, P=0.02\right)$. Total plasma carotenoids were higher in 1998 than in 1999 in both Dehesa de Abajo $(12.4 \pm 2.9 \mu \mathrm{g} / \mathrm{mL}, N=44$ vs. $9.9 \pm 3.7 \mu \mathrm{g} / \mathrm{mL}, N=54)$ and Jeréz $(2.8 \pm 0.7 \mu \mathrm{g} / \mathrm{mL}, N=11$ vs. $1.1 \pm 0.3 \mu \mathrm{g} / \mathrm{mL}, N=12)$. This trend was opposite for Arahal, although it could be influenced by the small sample size (Fig. 1). After controlling for the preceding effects, we found that crayfish-eating storks still differed from storks in other populations in plasma carotenoid contents $\left(F_{1,157}=218, P<0.001\right)$.

\section{Carotenoid Identification}

TLC showed that the extract from the plasma of five randomly selected crayfish-eating storks showed a single red band, coincidental in color and relative mobility (i.e., Rf value) with those of reference astaxanthin, crayfish, fat, and skin extracts from the adult stork. In 10 randomly selected storks from the colonies where crayfish were not present in the diet, there was a single yellow band identical to reference lutein. The electronic absorption spectra of plasma, skin, and fat from crayfish-eating storks, crayfish, and reference astaxanthin were the same, all showing a broad absorption band and single absorption maxima at $468 \mathrm{~nm}$ in hexane. The plasma samples from the remaining storks showed absorption spectra shaped like the reference lutein spectrum.

\section{Discussion}

It is well known from feeding experiments of birds in captivity (Hill 1993) and from zoo keeping (Fox and McBeth 1970) that carotenoid additives enhance plumage colors in birds with carotenoid-based plumage. However, few measurements of carotenoids in the plasma transport system are available (Brush 1981), and interpretation of some results is controversial. Fox and McBeth (1970) supplemented the diet of flamingos with astaxanthin, but plasma carotenoid levels actually dropped. Hudon (1994) criticized experiments that used canthaxanthin because this pigment is unusual in natural bird diets.

The pioneering study by Slagsvold and Lifjeld (1985) clearly linked intrapopulation variation in plumage brightness to carotenoid content in the diet, but plasma carotenoid levels were not determined. More recently, Hill et al. (1994) reported in- 
terpopulation variation in plasma carotenoid levels that could be attributable to diet, but the latter was not examined. Therefore, our study constitutes a demonstration of differences in plasma carotenoid levels among populations of the same bird species that result from variation in the carotenoid content and composition in the diet. Total plasma carotenoids were about five times higher in nestling storks whose diet was primarily crayfish compared to nestlings that ate typical foods. In fact, there was no overlap in carotenoid values between the two diet groups. In an interspecific study on plasma carotenoid levels involving 26 bird species, Tella et al. (1998) reported a mean carotenoid concentration of $9.4 \mu \mathrm{g} / \mathrm{mL}$ (range $0.43-74.16 \mu \mathrm{g} /$ $\mathrm{mL}$ ). Taking these data as a reference, we found that crayfisheating storks showed above-average carotenoid concentration, whereas those of the other nestlings were in the low range for birds.

Crayfish are indeed a rich source of astaxanthin, and our results demonstrate that this pigment was able to reach the blood of nestling storks. We can thus conclude that this newly available carotenoid in the environment is absorbed in large quantities and that the mechanisms responsible for the transport of carotenoids in the stork are not selective against astaxanthin.

White storks do not have carotenoids in their feathers, but because of carotenoids, adults show an intense red color in the bill, legs, and bare skin of the chin and throat. In nestling storks, the color of the bill and legs is typically black with interspersed dull orange parts. We noticed that nestlings in the Dehesa de Abajo colony presented a red color in the legs and bill, similar to that in adults, as well as intense and uniform orange coloration in the skin, particularly under the wings and on the abdomen. Nestlings in the other colonies presented whitish (unpigmented) skin. These observations and the qualitative carotenoid determinations that we performed on the dead adult stork indicate that the astaxanthin ingested by crayfish-eating storks diffused from the blood to the integument, probably ir $\rightarrow$ a nonspecific form, as suggested by Hudon (1994) for cases in which carotenoids are present in large quantities. It is noteworthy that carotenoids did not appear in the feathers; thi: suggests that physiological processes regulate which tissues are suitable targets for deposition and which are not. Yellow skin coloration caused by ingestion of large amounts of lutein has been reported in humans (Mathews-Roth 1981). This condition has been called "carotenodermia," a name that we might well apply to the crayfish-eating storks. In birds, a case of change in the normal pigmentation has recently been reported (Hudon and Brush 1989; Brush 1990b) for the plumage of free-living cedar waxwings (Bombycilla cedrorum) in the United States. The color shift from yellow to orange was linked to the consumption of fruits of an introduced shrub containing rhodoxanthin, a carotenoid pigment not present in the typical diet $\mathrm{o} \rightarrow$ cedar waxwings.

Consumption of crayfish by white storks is not likely to be a rarity in the near future. Red swamp crayfish are quickly expanding in Spain (Senra and Alés 1992) and can be found in many rivers and reservoirs in the southern part of the country. This species has been recently introduced in other European countries, such as Italy and France, where white storks occur and may incorporate the crayfish into their diets. Given that carotenoids may provide health benefits as antioxidants (Bendich 1989; Lozano 1994; Surai and Speake 1998), further research is needed to determine whether storks with high levels of astaxanthin caused by ingesting the crayfish will have any physiological effects compared with storks showing only moderate to low levels of lutein.

\section{Acknowledgments}

We thank the personnel of the Equipo de Seguimiento de Procesos Naturales for their help in collecting samples in the Dehesa de Abajo. J. Marchamalo and M. de la Riva shared unpublished data on diet and movements of white storks in Madrid province and Arahal, respectively. The staff of Jeréz Zoo (M. A. Quevedo, I. Sánchez, J. M. Aguilar, and M. Barcell) helped to sample the storks from the zoo. Comments from two referees greatly improved the manuscript. J.J.N., J.L.T., G.B., and M.G.F. were supported by postdoctoral grants from the Consejo Superior de Investigaciones Científicas and Ministerio de Educación y Ciencia, respectively. J. A. Godoy performed the molecular sexing. The North Atlantic Treaty Organization (NATO) supported our research on carotenoids through its Collaborative Research Grant Programme.

\section{Literature Cited}

Bendich A. 1989. Carotenoids and the immune response. Am J Nutr 119:112-115.

Blanco G. 1996. Population dynamics and communal roosting of white storks foraging at a Spanish refuse dump. Colon Waterbirds 19:273-276.

Bortolotti G.R., J.J. Negro, J.L. Tella, T.A. Marchant, and D.M. Bird. 1996. Sexual dichromatism in birds independent of diet, parasites and androgens. Proc R Soc Lond B Biol Sci 263:1171-1176.

Britton G. 1995. UV/Visible spectroscopy. Pp. 13-62 in G. Britton, S. Liaaen-Jensen, and H. Pfander, eds. Carotenoids: Spectroscopy. Vol. 1B. Birkhauser, Basel.

Brush A.H. 1981. Carotenoids in wild and captive birds. Pp. 539-562 in J.C. Bauernfeind, ed. Carotenoids as Colorants and Vitamin A Precursors. Academic Press, New York.

- 1990a. Metabolism of carotenoid pigments in birds. FASEB J 4:2969-2977.

$\rightarrow-1990 b$. A possible source for the rhodaxanthin in some cedar waxwing tails. J Field Ornithol 61:355.

Chozas P. 1983. Estudio general sobre la población de la di- 
námica de población de la cigüeña Ciconia ciconia en España $\rightarrow$ Lozano G. 1994. Carotenoids, parasites, and sexual selection. PhD diss. Universidad Complutense de Madrid.

Oikos 70:309-311.

$\rightarrow$ Delibes M. and M.I. Adrián. 1987. Effects of crayfish introduction on otter Lutra lutra food in the Doñana National Park, SW Spain. Biol Conserv 42:153-159.

$\rightarrow$ Ellegren H. 1996. First gene on the avian W chromosome (CHD) provides a tag for universal sexing of non-ratite birds. Proc R Soc Lond B Biol Sci 263:1635-1641.

Figuerola J. and R. Gutiérrez. 1998. Sexual differences in levels of blood carotenoids in the cirl bunting (Emberiza cirlus). Ardea 86:245-248.

Fox D.L. 1953. Animal Biochromes and Structural Colours. Cambridge University Press, Cambridge.

Mathews-Roth M.M. 1981. Carotenoids in medical applications. Pp. 755-785 in J.C. Bauernfeind, ed. Carotenoids as Colorants and Vitamin A Precursors. Academic Press, New York.

$\rightarrow$ Mínguez-Mosquera M.I. and J. Garrido-Fernández. 1989. Chlorophyll and carotenoid presence in olive fruit (Olea europaea). J Agr Food Chem 37:1-7.

Muriana F.J.G., V. Ruiz-Gutierrez, M.L. Gallardo-Guerrero, and M.I. Mínguez-Mosquera. 1993. A study of the lipids and carotenoprotein in the Prawn, Penaeus japonicus. J Biochem 114:223-229.

$\rightarrow$ Fox D.L. and J.W. McBeth. 1970. Some dietary carotenoids anc blood carotenoid levels in flamingos. Comp Biochem Physiol 34:707-713.

$\rightarrow$ Gray D.A. 1996. Carotenoids and sexual dichromatism in North American passerine birds. Am Nat 148:453-480.

$\rightarrow$ Hill G.E. 1991. Plumage colouration is a sexually selected indicator of male quality. Nature 350:337-339.

$\rightarrow$. 1993. The proximate basis of inter- and intra-population variation in female plumage colouration in the house finch. Can J Zool 71:619-627.

$\rightarrow-1995 a$. Interspecific variation in plasma hue in relation to carotenoid plumage pigmentation. Auk 112:1054-1057.

$\rightarrow \longrightarrow$. 1995b. Seasonal variation in circulating carotenoid pigments in the house finch. Auk 112:1057-1061.

Negro J.J., G.R. Bortolotti, J.L. Tella, K.J. Fernie, and D.M. Bird. 1998. Regulation of integumentary colour and plasma carotenoids in American kestrels consistent with sexual selection theory. Funct Ecol 12:307-312.

$\rightarrow$ Olson V.A. and I.P.F. Owens. 1998. Costly sexual signals: are carotenoids rare, risky or required? Trends Ecol Evol 13: 510-514.

Rubio J.C., M. Rodríguez, and R. Santo-Rosa. 1983. Reproduction de la cicogne blanche (Ciconia ciconia) dans les Marismas du Guadalquivir (Espagne). Alauda 51:251-258.

$\rightarrow$ Senra A. and E.E. Alés. 1992. The decline of the white stork Ciconia ciconia population of western Andalusia between 1976 and 1978: causes and proposals for conservation. Biol Conserv 61:51-57.

$\rightarrow$ Hill G.E., R. Montgomerie, C.Y. Inouye, and J. Dale. 1994. Influence of dietary carotenoids on plasma and plumage colour in the house finch: intra- and intersexual variation. Func Ecol 8:343-350.

$\rightarrow$ Hudon J. 1994. Showiness, carotenoids and captivity: a comment on Hill (1992). Auk 111:218-221.

$\rightarrow$ Hudon J. and A.H. Brush. 1989. Probable dietary basis of a color variant of the cedar waxwing. J Field Ornithol 60: 361-368.

$\rightarrow$ Linville S.U. and R. Breitwisch. 1997. Carotenoid availability and plumage coloration in a wild population of northern cardinals. Auk 114:796-800.

$\rightarrow$ Slagsvold T. and J.T. Lifjeld. 1985. Variation in plumage colour of the great tit in relation to habitat, season and food. J Zool (Lond) 206:321-328.

$\rightarrow$ Surai P. and B.K. Speake. 1998. Distribution of carotenoids from the yolk to the tissues of the chick embryo. J Nutr Biochem 9:645-651.

$\rightarrow$ Tella J.L., J.J. Negro, R. Rodríguez-Estrella, G. Blanco, M.G. Forero, M.C. Blázquez, and F. Hiraldo. 1998. A comparison of spectrophotometry and color charts for evaluating total plasma carotenoids in wild birds. Physiol Zool 71:708-711.

Trams E.G. 1969. Carotenoid transport in the plasma of the scarlet ibis (Eudocimus ruber). Comp Biochem Physiol 8: 1177-1184. 